\title{
Reduction of weather effects in the calculation of sea-ice concentration with the DMSP SSM/I
}

\author{
Donald J. Cavalieri, \\ Laboratory for Hydrospheric Processes, Code 971, NASA Goddard Space Flight Center, Greenbelt, Maryland 20771, U.S.A. \\ Karen M. St. Germain, \\ Department of Electrical Engineering, University of Nebraska, Lincoln, Nebraska 68588, U.S.A. \\ Calvin T. SwifT \\ Department of Electrical and Computer Engineering, University of Massachusetls, Amherst, Massachusetts 01003, U.S.A.
}

\begin{abstract}
A problem in mapping the polar sea-ice covers in both hemispheres has been the sporadic false indication of sea ice over the open ocean and at the ice edge. These spurious sea-ice concentrations result from variations in sea-surface roughening by surface winds, atmospheric water vapor and both precipitating and non-precipitating liquid water. This problem was addressed for sea-ice concentrations derived from the Nimbus-7 scanning multi-channel microwave radiometer (SMMR) data through the development of a weather filter based on spectral information from the 18.0 and $37.0 \mathrm{GHz}$ vertical polarization SMMR channels. Application of a similar filter for use with sea-ice concentration maps derived with the special-sensor microwave imager $(\mathrm{SSM} / \mathrm{I})$ sensor is less successful. This results from the position of the $19.35 \mathrm{GHz} \mathrm{SSM} / \mathrm{I}$ channels, which are closer to the center of the $22.2 \mathrm{GHz}$ atmospheric water-vapor line than are the SMMR $18.0 \mathrm{GHz}$ channels. Thus, the $\mathrm{SSM} / \mathrm{I} 19.35 \mathrm{GHz}$ channels are more sensitive to changes in atmospheric water vapor, which results in greater contamination problems. An additional filter has been developed, based on a combination of the 19.35 and $22.2 \mathrm{GHz}$ SSM/I channels. Examples of the effectiveness of the new filter are presented and limitations are discussed.
\end{abstract}

\section{INTRODUCTION}

A problem in mapping the polar sea-ice concentrations in both hemispheres has been the false indication of sea ice over the open ocean and at the ice edge. These spurious sea-ice concentrations result from the presence of atmospheric water vapor, non-precipitating cloud liquid water, rain and sea-surface roughening by surface winds. While these effects are relatively minor at polar latitudes in winter, they result in serious weather contamination problems at all latitudes in summer (Gloersen and Cavalieri, 1986; Cavalieri and others, 1992).

The severity of weather contamination on Defense Meteorological Satellite Program (DMSP) Special Sensor Microwave/Imager (SSM/I) sea-ice concentration in summer is illustrated in Figure 1 for both the Northern (18 August 1988) and Southern (5 February 1989) Hemispheres. Figure la shows large spurious sea-ice concentrations as high as $100 \%$ in the Pacific Ocean, $35 \%$ adjacent to the Kamchatka Peninsula and as high as $50 \%$ adjacent to Newfoundland. Over the Southern Ocean (Fig. 1b), spurious concentrations of up to $35 \%$ encircle Antarctica, with a maximum concentration of $80 \%$ north of the Weddell Sea. Although the following discussion focuses on the Arctic, the technique is equally applicable to the Antarctic.

The problem was addressed for sea-ice concentrations derived from the Nimbus-7 Scanning Multichannel Microwave Radiometer (SMMR) data through the development of a weather filter (Gloersen and Cavalieri, 1986). The filter is based on the polarization (PR) and the spectral gradient ratio $(\mathrm{GR})$ distribution of ice-free and ice-covered seas. PR is defined in terms of the $18.0 \mathrm{GHz}$ channels (PR 18) and GR is defined in terms of the 18.0 and $37.0 \mathrm{GHz}$ channels (GR $(37 / 18)$ ). Gloersen and Cavalieri used a semi-empirical radiative-transfer model (RTM) to calculate PR (18) and GR (37/18) values for various atmospheric and sea-surface conditions. The (PR, GR) distributions obtained are illustrated for both the Arctic (Fig. 2a) and Antarctic (Fig. 2b) for typical wintertime conditions. Figure 2 also illustrates the sensitivity in (PR, GR) resulting from changes in seasurface temperature (SST), near-surface wind (NSW), cloud liquid water $(\mathrm{L})$ and atmospheric water vapor $(\mathrm{W})$. Each plot in Figure 2 also shows the NASA team algorithm triangle defined by the vertices for open water (OW), first-year (FY) and multi-year (MY) sea ice.

In Figure 2, each value calculated from the RTM is 


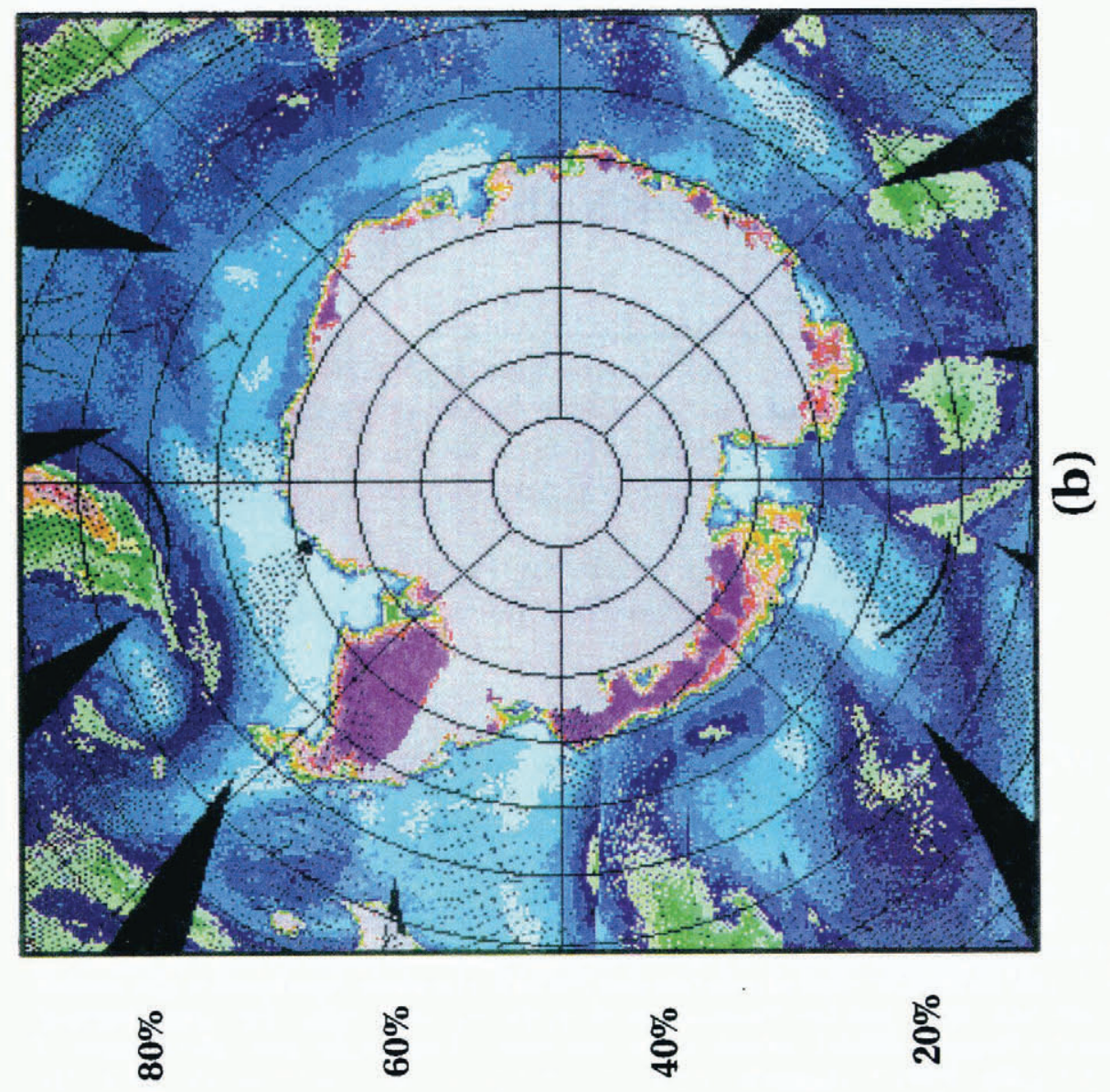


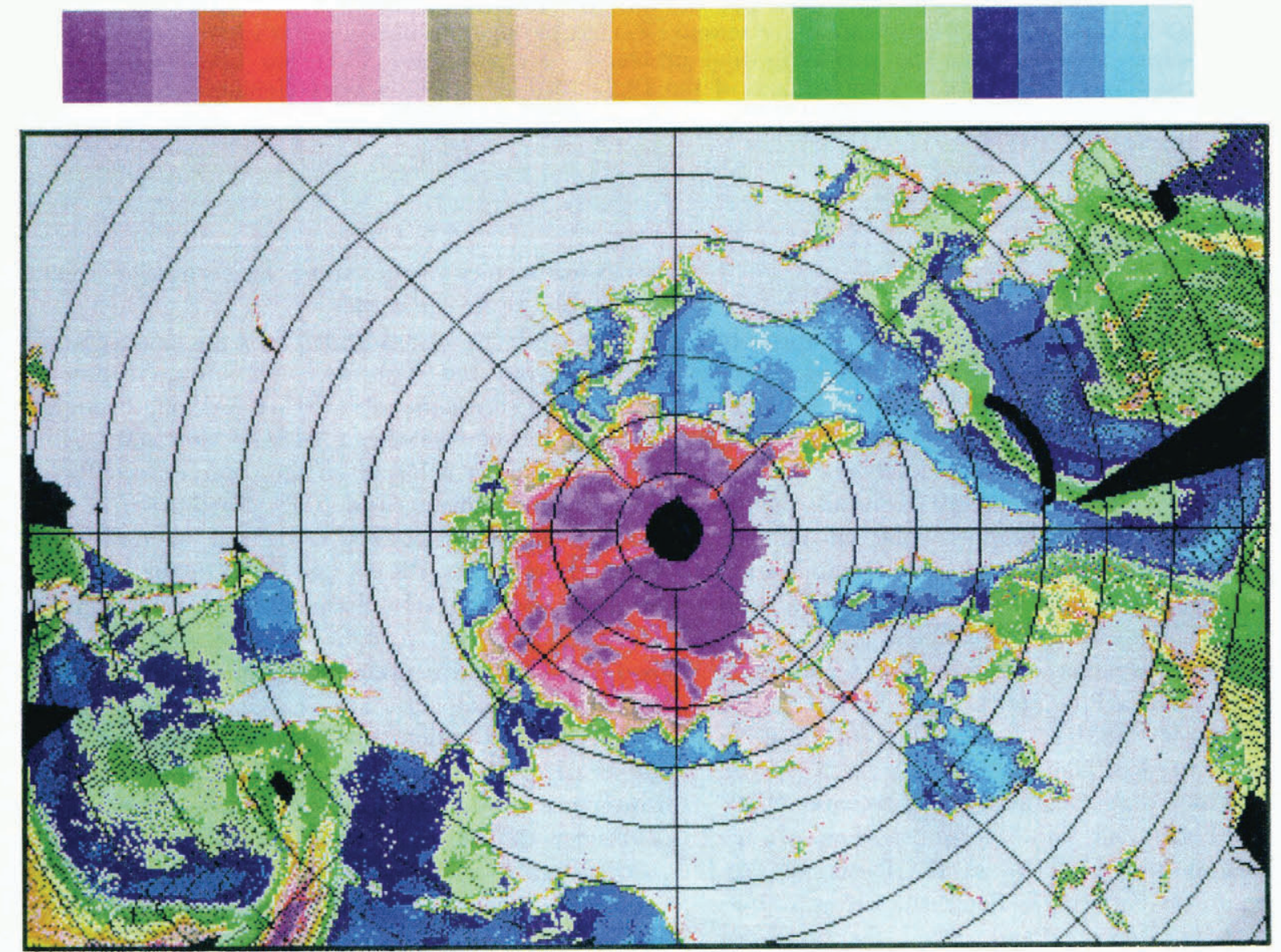


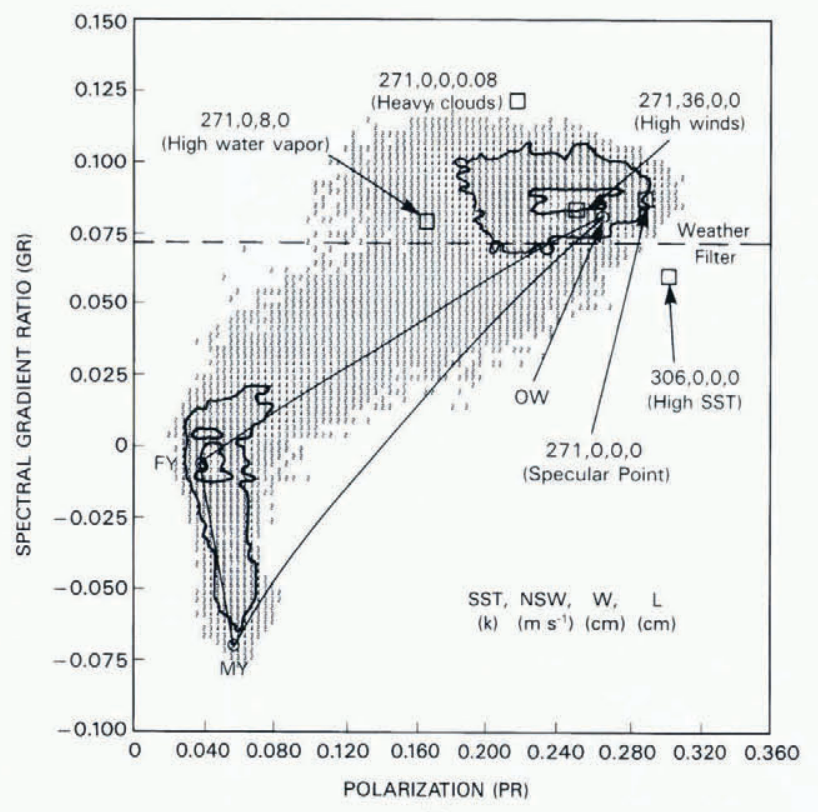

(a)

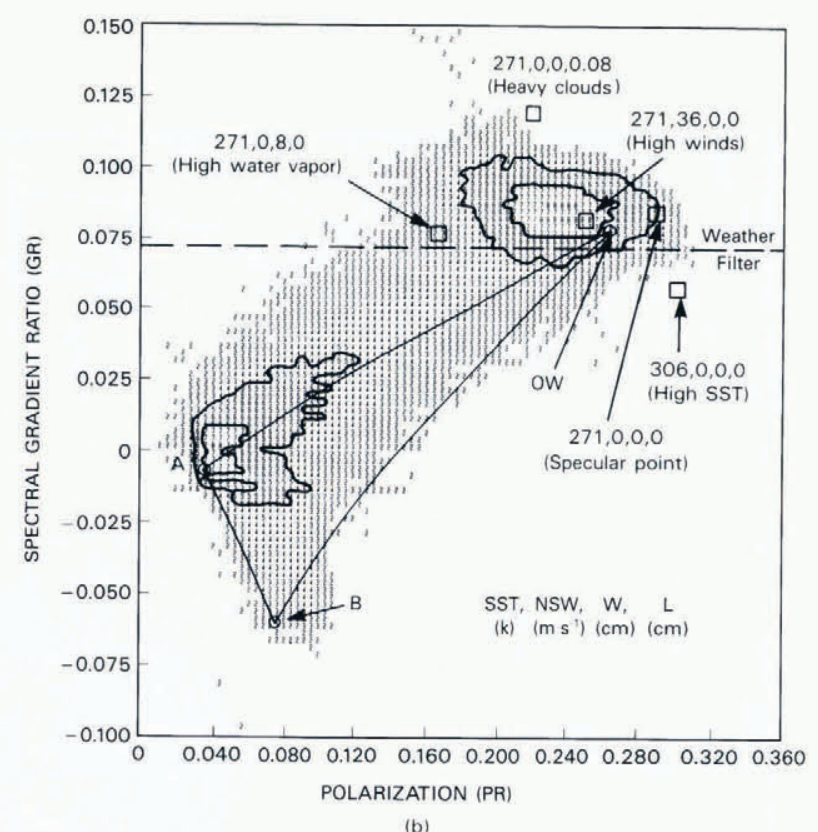

(b)

Fig. 2. SMMR spectral gradient ratio GR(37/18) vs polarization PR (18) for (a) the Arctic for 3-7 February 1979, and (b) the Antarctic for 27-31 October 1986, showing the effects of ocean temperature, winds and atmospheric cloud liquid water and water vapor. (From Gloersen and others (1992).)

given in brackets using the convention: [SST, NSW, L, W]. The first point plotted corresponds to a specular ocean (no winds, clouds or atmospheric water vapor) at the freezing point $(271 \mathrm{~K})$ and is labeled [271, 0, 0, 0]. Next, the RTM was run, varying one parameter at a time. The SST changed from $271 \mathrm{~K}$ to $306 \mathrm{~K}[306,0,0$, $0]$; $\mathrm{NSW}$ changed to $36 \mathrm{~m} \mathrm{~s}^{-1}$; $\mathrm{L}$ to $0.08 \mathrm{~cm}$; and $\mathrm{W}$ to $8 \mathrm{~cm}$. These points span the region of the OW cluster and thus provide information on the various contributing conditions giving rise to the observed distribution in (PR, GR space. By changing only SST, the point moves to the lower left of the main OW cluster, an area devoid of data, indicating that there are no warm SSTs with no wind and a dry atmosphere in the region mapped. However, the main cluster is bounded by the other three points, together with the specular point, which indicates that variations in wind, cloud and water vapor result in the observed scatter of points over OW areas.

The weather filter for the Nimbus-7 SMMR sea-ice algorithm consists of setting the sea-ice concentration to zero if $\mathrm{GR}(37 / 18)$ is greater than 0.08 . While this threshold technique is effective in eliminating most of the spurious sea-ice concentrations, it also eliminates actual sea-ice concentrations less than $12 \%$ for first-year ice and $8 \%$ for multi-year ice Gloersen and Cavalieri, 1986). This is not considered a serious problem for most applications, since the ice edge has previously been defined as the $15 \%$ ice-concentration contour as determined from satellite radiometers.

Application of a GR (37/19) filter for use with sea-ice concentration maps derived with the SSM/I sensor is less successful. Figure 3a shows an SSM/I sea-ice concentration map for 23 June 1988, generated with the GR (37/ 19) threshold filter. Erroneous ice concentrations up to about $50 \%$ are found over open oceans at low latitudes. The difference in effectiveness of this filter results from the closer proximity of the $19.4 \mathrm{GHz} \mathrm{SSM} / \mathrm{I}$ channels to the center of the $22.2 \mathrm{GHz}$ atmospheric water-vapor line than that of the $18.0 \mathrm{GHz}$ SMMR channels. As shown below in section 2, the proximity of the $19.4 \mathrm{GHz}$ channel to the $22.2 \mathrm{GHz}$ water-vapor line is used to provide an improved weather filter (Fig. 3b).

A plot of the atmospheric water-vapor attenuation coefficient for a frequency range of $10-30 \mathrm{GHz}$ is shown in Figure 4. The attenuation coefficient was calculated using the formulation given by Ulaby and others (1981) and, assuming standard sea-level pressure, a surface temperature of $300 \mathrm{~K}$, and a water-vapor density of $1 \mathrm{~g} \mathrm{~m}^{-3}$. Examination of Figure 4 shows that $18.0 \mathrm{GHz}$ is about one-third up the wing of the water-vapor line, whereas 19.34 GHz is about half-way up the line. Thus, the SSM/I $19.35 \mathrm{GHz}$ channels are more sensitive to changes in atmospheric water vapor. This sensitivity results in greater contamination problems.

\section{PHYSICAL BASIS OF THE SSM/I FILTER}

In this section, we briefly review the microwave polarization and spectral dependency of emission by ocean and atmosphere for the purpose of describing the physical basis of the SSM/I weather filter. The general theory of microwave emission from the ocean, atmosphere and ice-covered surfaces has been reviewed elsewhere Gloersen and Barath, 1977; Swift, 1980; Wilheit and Chang, 1980; Gloersen and others, 1992; St. Germain, 1993).

The radiation received by the satellite and expressed as a brightness temperature $\left(T_{\mathrm{B}}\right)$ consists of several components

$$
\begin{aligned}
T_{\mathrm{B}, \lambda, \mathrm{p}} & =\epsilon_{\lambda, \mathrm{p}} T_{\mathrm{s}} \mathrm{e}^{-\kappa_{\lambda}} \\
& +T_{\mathrm{B}, \lambda, \mathrm{up}}+\left(1-\epsilon_{\lambda, \mathrm{p}}\right) T_{\mathrm{B}, \lambda, \text { down }}+\left(1-\epsilon_{\lambda, \mathrm{p}}\right) T_{\mathrm{B}, \mathrm{c}} \mathrm{e}^{-2 \kappa_{\lambda}}
\end{aligned}
$$



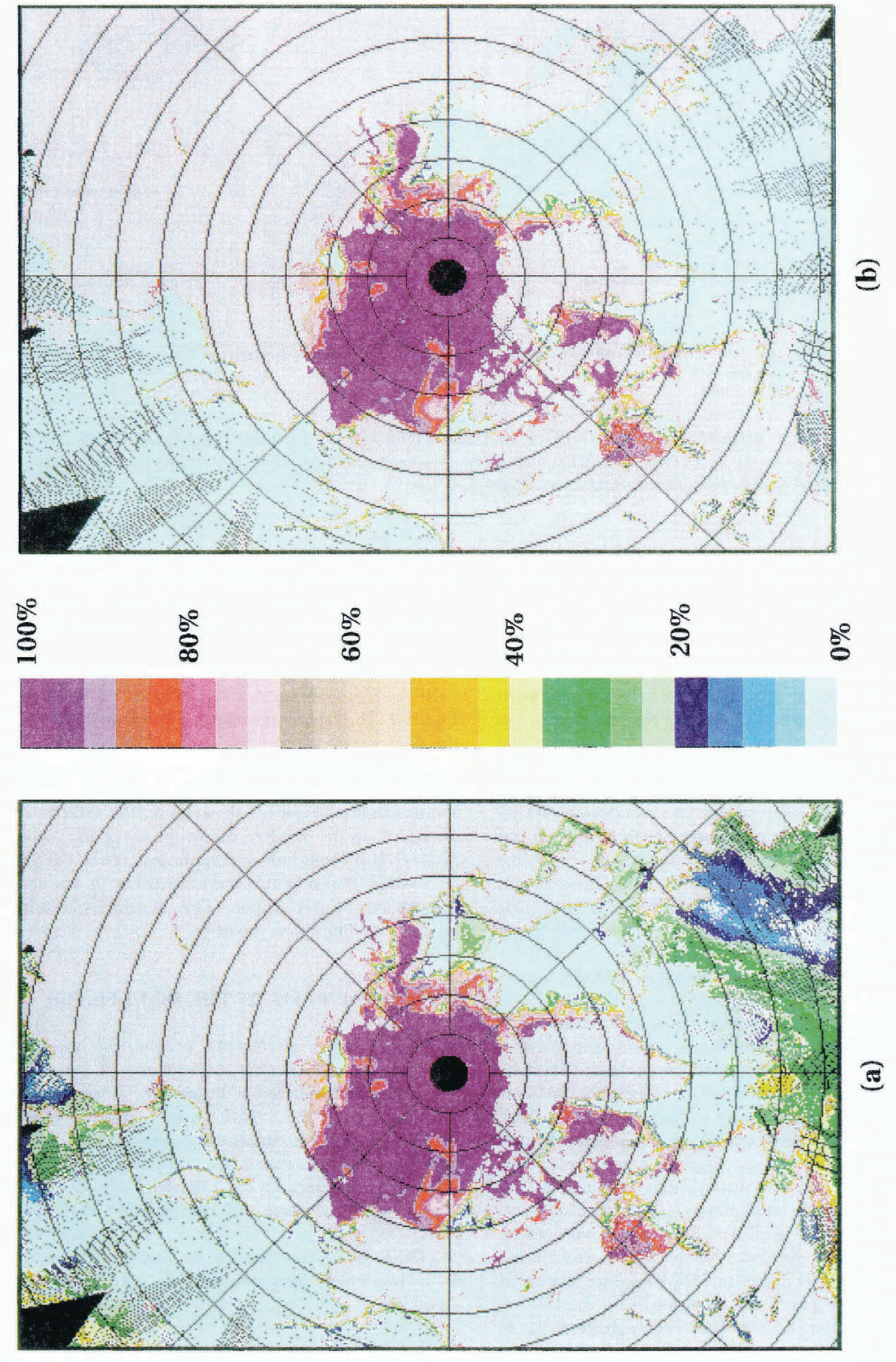


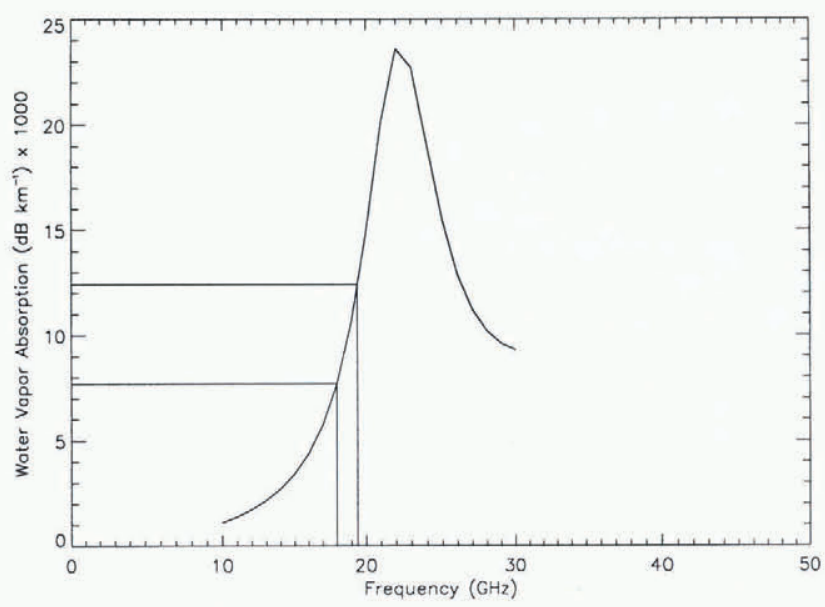

Fig. 4. Atmospheric water-vapor absorption coefficient as a function of frequency for standard sea-level pressure, a surface temperature of $300 \mathrm{~K}$ and a water-vapor density of $1 \mathrm{~g} \mathrm{~m}^{-3}$, following the formulation of Ulaby and others (1981).

where $T_{\mathrm{B}, \lambda, \mathrm{p}}$ is measured brightness temperature as a function of wavelength $(\lambda)$ and polarization $(\mathrm{p}), \epsilon_{\lambda, \mathrm{p}}$ is total surface emissivity, $T_{\mathrm{S}}$ is physical temperature of the surface, $\kappa_{\lambda}$ is atmospheric opacity, $T_{\mathrm{B}, \lambda \text {,up }}$ is total atmospheric upwelling radiation, $T_{\mathrm{B}, \lambda \text {,down }}$ is total atmospheric downwelling radiation and $T_{\mathrm{B}, \mathrm{c}}$ is cosmic background radiation $(2.7 \mathrm{~K})$.

The microwave emission $\left(\epsilon_{\lambda, \mathrm{p}}\right)$ from the ocean surface is a function of wavelength, polarization, angle of incidence, surface temperature and salinity. The surface emissivity will increase with increasing wavelength but will decrease with increasing surface temperature. Seasurface salinity variability affects the emissivity only at wavelengths longer than about $6 \mathrm{~cm}$ (Wilheit and Chang, 1980 ) and so is not of concern here, because all SSM/I wavelengths are $1.55 \mathrm{~cm}$ or shorter. The change in emissivity with angle of incidence depends on the polarization. Emissivity increases with angle of incidence at vertical polarization and decreases with increasing angle of incidence at horizontal polarization. Because the $\mathrm{SSM} / \mathrm{I}$ is a conically scanning radiometer, its angle of incidence is constant at $53^{\circ}$.

In addition to an increase in sea-surface temperature, the presence of a surface wind will also increase the surface microwave emission through the roughening of the sea surface. The amount of increase again depends on wavelength and angle of incidence. For example, at a wavelength of $1.55 \mathrm{~cm}$, the radiometric brightness increases by $1.2 \mathrm{~K}$ at $0^{\circ}$ angle of incidence to about $1.8 \mathrm{~K}$ at $70^{\circ}$ for each $\mathrm{m} \mathrm{s}^{-1}$ increase in wind speed (Nordberg and others, 1971).

Atmospheric emission will also contribute to the radiometric brightness temperature measured by the satellite through the atmospheric opacity term $(\kappa)$ in Equation (1). The opacity depends on the total integrated amount of atmospheric oxygen, water vapor, non-precipitating cloud liquid water and rain through the entire atmosphere along the line of sight of the radiometer. The contribution from oxygen is a constant for a given wavelength as is the cosmic background radiation term $\left(T_{\mathrm{B}, \mathrm{c}}\right)$ in Equation (1). The atmospheric variables of interest then are the water vapor $(V)$, non-precipitating cloud liquid water $(L)$ and rain rate $(R)$.

The total atmospheric opacity $(\kappa)$ may be approximated by

$$
\kappa=\kappa_{\text {vap }}+\kappa_{\text {liq }}+\kappa_{\text {oxy }}+\kappa_{\text {rain }} .
$$

For oxygen, water vapor and cloud liquid water, we use the following linear expressions following St. Germain (1993):

$$
\begin{aligned}
\kappa_{\text {vap }} & =A V \\
\kappa_{\text {liq }} & =B L \\
\kappa_{\text {oxy }} & =C
\end{aligned}
$$

where $A$ and $B$ are wavelength- and temperaturedependent coefficients linearly relating the total integrated quantity to opacity. $C$ is the wavelength-dependent coefficient for oxygen. The expressions for these coefficients have been derived by St. Germain (1993) and are given here for each of the three SSM/I frequencies of interest:

$$
\begin{aligned}
& A_{19}=\left(2.1+0.0005 T_{\mathrm{s}}\right) / 1000 \\
& A_{22}=\left(17.8+0.013 T_{\mathrm{s}}\right) / 1000 \\
& A_{37}=\left(4.4-0.0093 T_{\mathrm{s}}\right) / 1000 \\
& B_{19}=\left(89.7-0.263 T_{\mathrm{s}}\right) / 100 \\
& B_{22}=\left(90.7-0.264 T_{\mathrm{s}}\right) / 100 \\
& B_{37}=\left(298.4-0.903 T_{\mathrm{s}}\right) / 100 \\
& C_{19}=\left(2.69-0.0057 T_{\mathrm{s}}\right) / 100 \\
& C_{22}=\left(2.96-0.0063 T_{\mathrm{s}}\right) / 100 \\
& C_{37}=\left(7.95-0.0167 T_{\mathrm{s}}\right) / 100 .
\end{aligned}
$$

These expressions are used in the RTM for obtaining the brightness temperatures for various atmospheric conditions.

An approximate expression for the dependency of atmospheric opacity on rain rate has been given by Gloersen and Barath (1977):

$$
\kappa_{\text {rain }}=\left\{-a+\left[a^{1.2}+b^{1.2} R^{1.2}\right]^{0.833}\right\} h
$$

for $\kappa<0.4$ where $a=-3.51 \times 10^{-2}+5.55 \times 10^{-2} \lambda-$ $6.42 \times 10^{-3} \lambda^{2}, b=5.14 \times 10^{-2} \lambda^{-1.85}, R$ is rain rate in $\mathrm{mm} \mathrm{h}^{-1}$ and $h$ is height of the rain column $(\mathrm{km})$. The rainfall models used to derive these expressions assume a Marshall-Palmer distribution of rain droplets and utilize a calculation which includes Mie scattering and absorption (Gloersen and Barath, 1977).

Of direct relevance to the problem at hand is the variation of atmospheric water vapor, precipitating and non-precipitating liquid water, near-surface winds and rainfall rates on $P R$ and $G R$, the two independent variables used in the SSM/I sea-ice algorithm. PR(19)s and GR $(37 / 19)$ s were generated for a wide range of nearsurface winds, cloud liquid water and atmospheric water vapor using the radiative-transfer model described by St. Germain (1993). Similarly, (PR, GR) pairs were generated for a range of rain rates using the Wilheit and Chang (1980) model.

The variation of $P R$ and $G R$ with each of these atmospheric parameters is shown in Figure 5. The RTM 

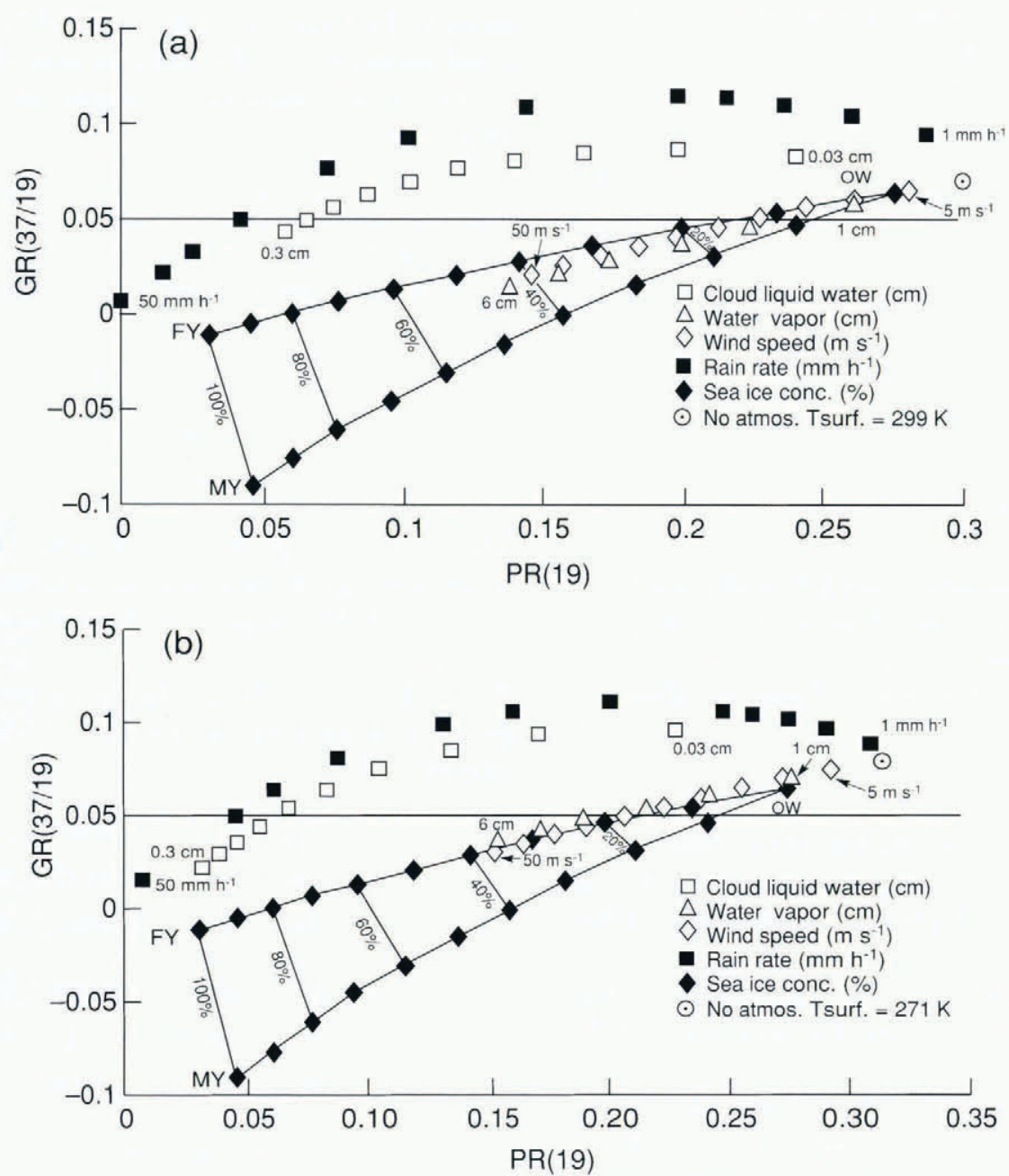

Fig. 5. PR(19) is GR(37/19) showing the distribution of surface wind speed $\left(0-50 \mathrm{~m} \mathrm{~s}^{-1}\right)$, cloud liquid water (0$0.3 \mathrm{~cm})$ and atmospheric water vapor $(0-6 \mathrm{~cm})$ and rain rate $\left(0-50 \mathrm{~mm} \mathrm{~h}^{-1}\right)$, calculated using radiative-transfer models with surface temperatures of (a) $299 \mathrm{~K}$ and (b) $271 \mathrm{~K}$. The GR(37/19) threshold value (0.05) was used in the first $S S M / I$ weather filter and is indicated by the horizontal solid line.

was run using ocean-surface temperatures of $299 \mathrm{~K}$ (Fig. $5 \mathrm{a}$ ) and $271 \mathrm{~K}$ (Fig. 5b) representative of mid and polar latitudes, respectively. As in Figure 2 for the SMMR, the $\mathrm{SSM} / \mathrm{I}$ sea-ice algorithm is represented in (PR, GR) space by a triangle with curvilinear sides. The GR $(37 / 19)$ threshold for the SSM/I is 0.05. For a sea-surface temperature of $299 \mathrm{~K}$, we see that this $\mathrm{GR}(37 / 19)$ threshold value eliminates cloud liquid-water amounts of up to $0.27 \mathrm{~cm}$, rain rates of up to $15 \mathrm{~mm} \mathrm{~h}^{-1}$, water vapor of up to almost $2 \mathrm{~cm}$ and wind speeds of up to $20 \mathrm{~m} \mathrm{~s}^{-1}$ (Fig. 5a). For an ocean-surface temperature of $271 \mathrm{~K}$, typical near the ice edge, the GR $(37 / 19)$ threshold eliminates cloud liquid-water amounts of up to $0.20 \mathrm{~cm}$, rain rates of up to $25 \mathrm{~mm} \mathrm{~h}^{-1}$, water vapor of less than $4 \mathrm{~cm}$ and wind speeds of up to $30 \mathrm{~m} \mathrm{~s}^{-1}$ (Fig. 5b). Since these atmospheric parameter values are seldom realized at polar latitudes, the GR $(37 / 19)$ filter generally works well in most cases. It is at lower latitudes or in summer with water-vapor values greater than $2 \mathrm{~cm}$ that the GR(37/19) filter fails.

At this threshold level, ice concentrations up to $15 \%$ are also eliminated. By adjusting the threshold to a lower GR value, more of the water-vapor effects would be eliminated but at the expense of eliminating ice concentrations greater than $15 \%$. The problem, then, is to eliminate the water-vapor effects, while minimizing the loss of ice-concentration information.

As Figure 4 shows, the proximity of the $19.4 \mathrm{GHz}$ channel to the $22.2 \mathrm{GHz}$ atmospheric water-vapor line is the reason for the greater SSM/I sensitivity to watervapor variations. However, this sensitivity can be turned to an advantage through the definition of an atmospheric water-vapor filter. The difference between the 22.2 and 19.4 GHz vertical polarization channels is highly sensitive to small increases in atmospheric water vapor in the range $0-4 \mathrm{~cm}$ and is used as the basis of the additional weather filter needed to eliminate the water-vapor contamination illustrated in Figure 3a. This difference is normalized by the sum of the brightness temperatures, thereby defining a new spectral gradient ratio, GR $(22 / 19)$ :

$$
\begin{aligned}
\mathrm{GR}(22 / 19)= & {[\mathrm{TB}(22 \mathrm{~V})-\mathrm{TB}(19 \mathrm{~V})] / } \\
& {[\mathrm{TB}(22 \mathrm{~V})+\mathrm{TB}(19 \mathrm{~V})] }
\end{aligned}
$$

The GR approach was chosen to help minimize the effect of ice-temperature variations in cases where we have a field of view with both ice-free and ice-covered seas. The rationale for this approach has been discussed in detail by Gloersen and Cavalieri (1986). A threshold value of 0.045 was selected for the GR $(22 / 19)$ filter as a trade-off 
between eliminating spurious sea-ice concentrations and losing low ice-concentration information at the ice edge. The effectiveness of this additional filter and the loss of sea-ice information is discussed next.

\section{DISGUSSION OF RESULTS}

A plot of $\mathrm{GR}(37 / 19)$ versus $\mathrm{GR}(22 / 10)$ illustrates the potential effectiveness of each filter in eliminating the effects of each of the atmospheric components (Fig. 6). The chosen threshold values for each GR are also indicated in the figure by horizontal and vertical lines. As was noted in the discussion of Figure $5 \mathrm{a}$, a threshold value of 0.05 for $\mathrm{GR}(37 / 19)$ eliminates cloud liquid-water amounts of up to $0.27 \mathrm{~cm}$, rain rates of up to $15 \mathrm{~mm} \mathrm{~h}^{-1}$, water vapor of less than about $2 \mathrm{~cm}$ and wind speeds of up to $20 \mathrm{~m} \mathrm{~s}^{-1}$ from contributing to spurious sea-ice concentrations at low latitudes. From Figure 6, we see that the GR $(22 / 19)$ threshold of 0.045 is effective only for water vapor. All other atmospheric variables fall below the 0.045 threshold. Thus, both GR filters are required.

The model results shown in Figure 6 also help determine the conditions under which both filters will fail. The horizontal and vertical lines defined by the two threshold values define an area in the lower left part of the figure. Values of cloud liquid water, water vapor, wind speed and rain rates within this area will still result in spurious sea-ice concentrations. Extrapolation of these atmospheric parameters toward higher values tends toward the origin of the plot $(P R=0, G R=0)$, a condition corresponding to a perfect black-body emitter of radiation. Some examples of these extreme conditions are given below.

The sea-ice concentration map for 23 June 1988 is shown in Figure $3 \mathrm{~b}$ after the application of the additional GR $(22 / 19)$ filter. All of the spurious ice concentrations are filtered, except for two small areas of high concentration off the coast of Nova Scotia. These, as well as other examples of areas of spurious high ice concentrations, are not of particular concern, because they generally occur at latitudes where sea ice is known not to be present. Of much greater concern is the presence of spurious concentrations at or near the ice edge.

An ice-concentration difference map for 23 June shows the spurious ice concentrations that are filtered (Fig. 7). Except for two small areas, one in the Beaufort Sea near Banks Island and the other in the Barents Sea between Novaya Zemlya and Svalbard, the sea-ice edge is preserved and, as just noted, almost all of the spurious concentrations are filtered. The concern is that some actual ice-concentration information is lost in these two areas. Cloud cover precluded the use of AVHRR imagery to verify the location of the ice edge.

As an alternative test, the sea-ice concentration variability along two transects cutting across each of these two areas was examined to help determine which of the concentrations may be real and which concentrations result from passing weather systems. Presumably weatherrelated, spurious concentrations will show greater day-today variability. The first transect examined cuts across the ice from a point in the open-water area near Banks Island in the Beaufort Sea to a point well within the ice pack north of the area in question (see Fig. 7). The sea-ice concentrations are plotted in Figure 8 for a $4 \mathrm{~d}$ period from 21 to 24 June 1988. The four transects are plotted first from ice-concentration maps generated without the use of either weather filter (Fig. 8a and c) and then with both filters (Fig. 8b and d).

Without the use of weather filters and for all 4 days, ice concentrations range from $4 \%$ to $16 \%$ at pixel positions 0-4 (see Fig. 8a) and sharply increase at pixel position 5 until pixel 13 is reached. The ice concentrations then level off and vary from about $90 \%$ to $100 \%$ to the end of the transect (pixel position 21). Comparison of Figure 8a and b shows that for all 4 days, only those concentrations at pixel positions $0-4$ were eliminated by the filters. Since the ice concentrations $(90-100 \%)$ within the ice pack varied as much as those over the open-water area, one should consider the possibility that weather effects may

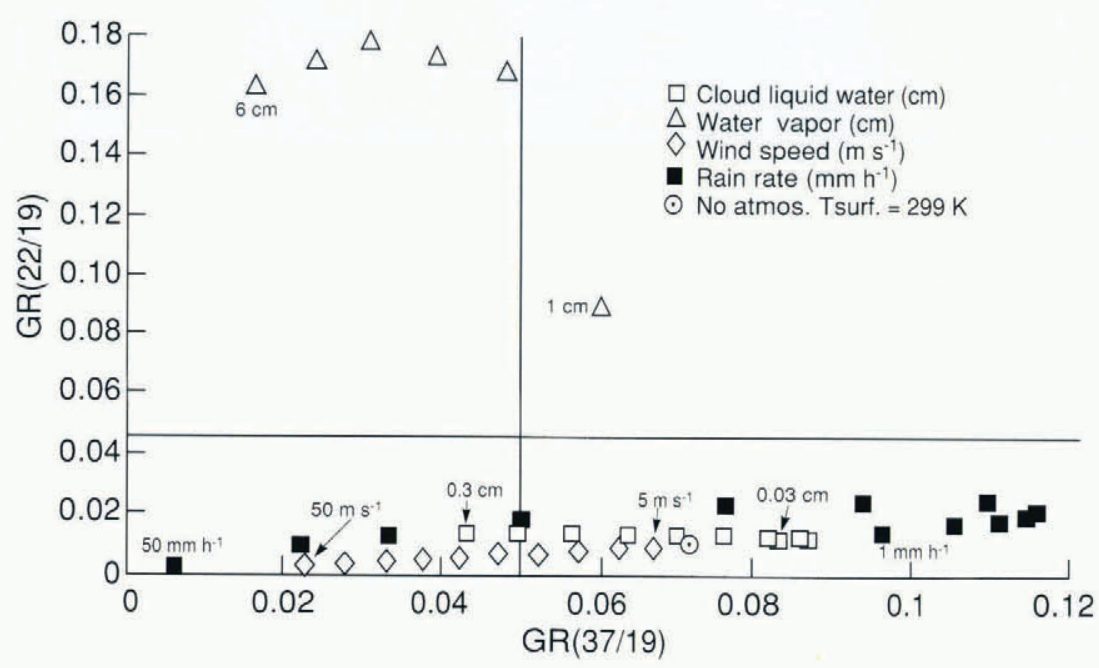

Fig. 6. GR(22/19) vs GR(37/19) showing the distribution of surface wind speed $\left(0-25 \mathrm{~m} \mathrm{~s}^{-1}\right)$, cloud liquid water (0 $0.3 \mathrm{~cm})$ and atmospheric water vapor $(0-5 \mathrm{~cm})$ and rain rate $\left(0-100 \mathrm{~mm} \mathrm{~h}^{-1}\right)$ calculated using radiative-transfer models. The GR(22/19) and GR(37/19) threshold values used in the SSM/I weather filter are indicated by the horizontal and vertical solid lines. 

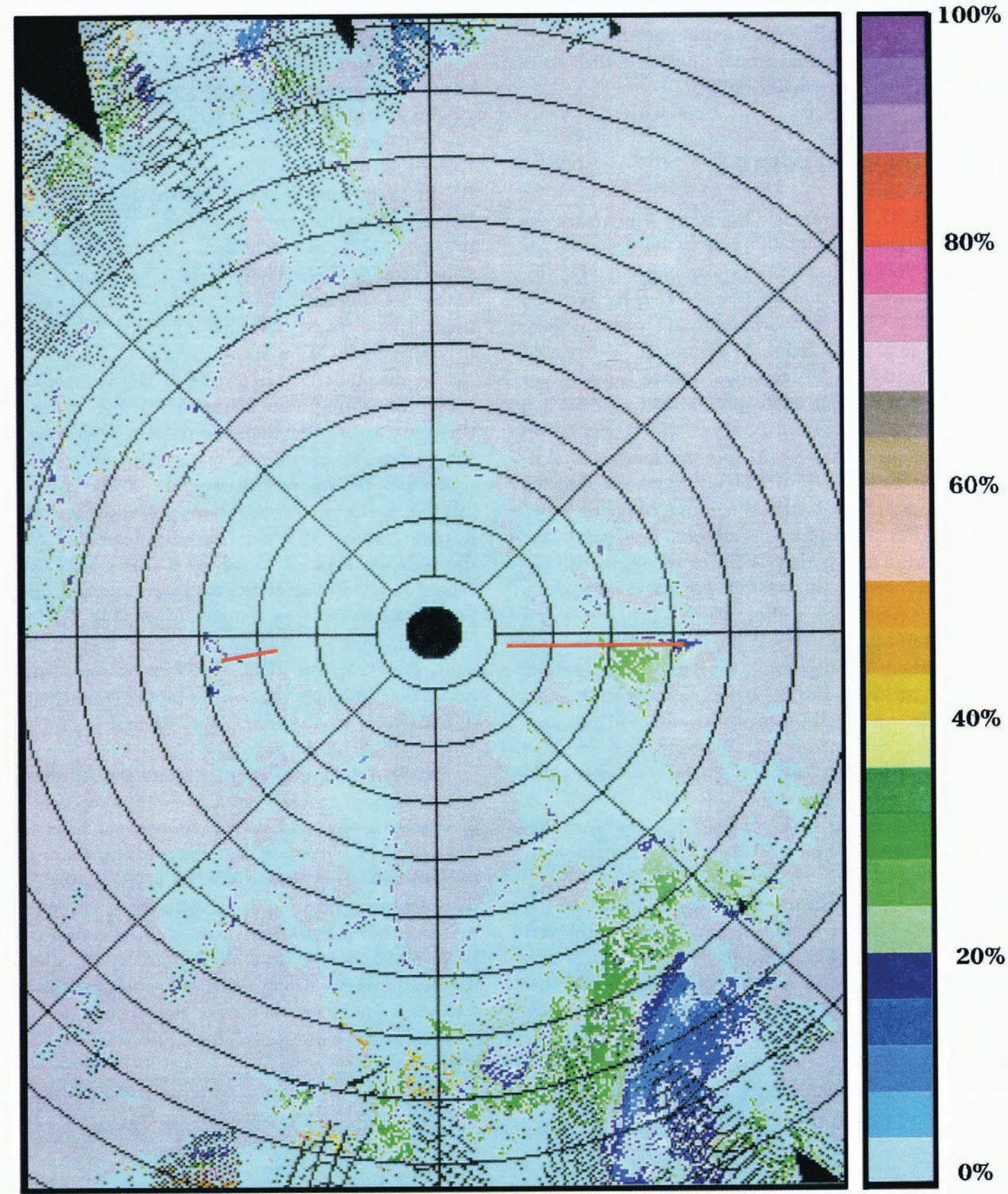

Fig. 7. Difference between the SSM/I sea-ice concentration maps shown in Figure 3. Sea-ice concentrations for transects shown in red are plotted in Figure 8.

contribute to some of this variability. A study by Maslanik (1992) has suggested that water vapor and cloud liquid water cause overestimates of total ice concentration over areas of high ice concentration, but the effects found were smaller than the observed variations here. The days with the highest (day 174) and lowest (day 172) concentrations over the polynya area (pixels $0-4$ ) have comparable concentrations within the pack ice (Fig. 8a). Thus, weather effects over the pack ice are apparently negligible.

The transect for the Barents Sea region (Fig. 8c and d) shows much greater ice-concentration variability starting from between pixel positions 45 and 50. This also corresponds to a sharp break in the rapid decrease in ice concentration (presumably the actual ice edge). Application of both weather filters in this case results in a sharp ice edge with zero concentrations at pixel positions ranging from 44 to 48 .

\section{SUMMARY}

The Nimbus-7 SMMR technique for filtering spurious sea-ice concentrations over open ocean and near the ice 

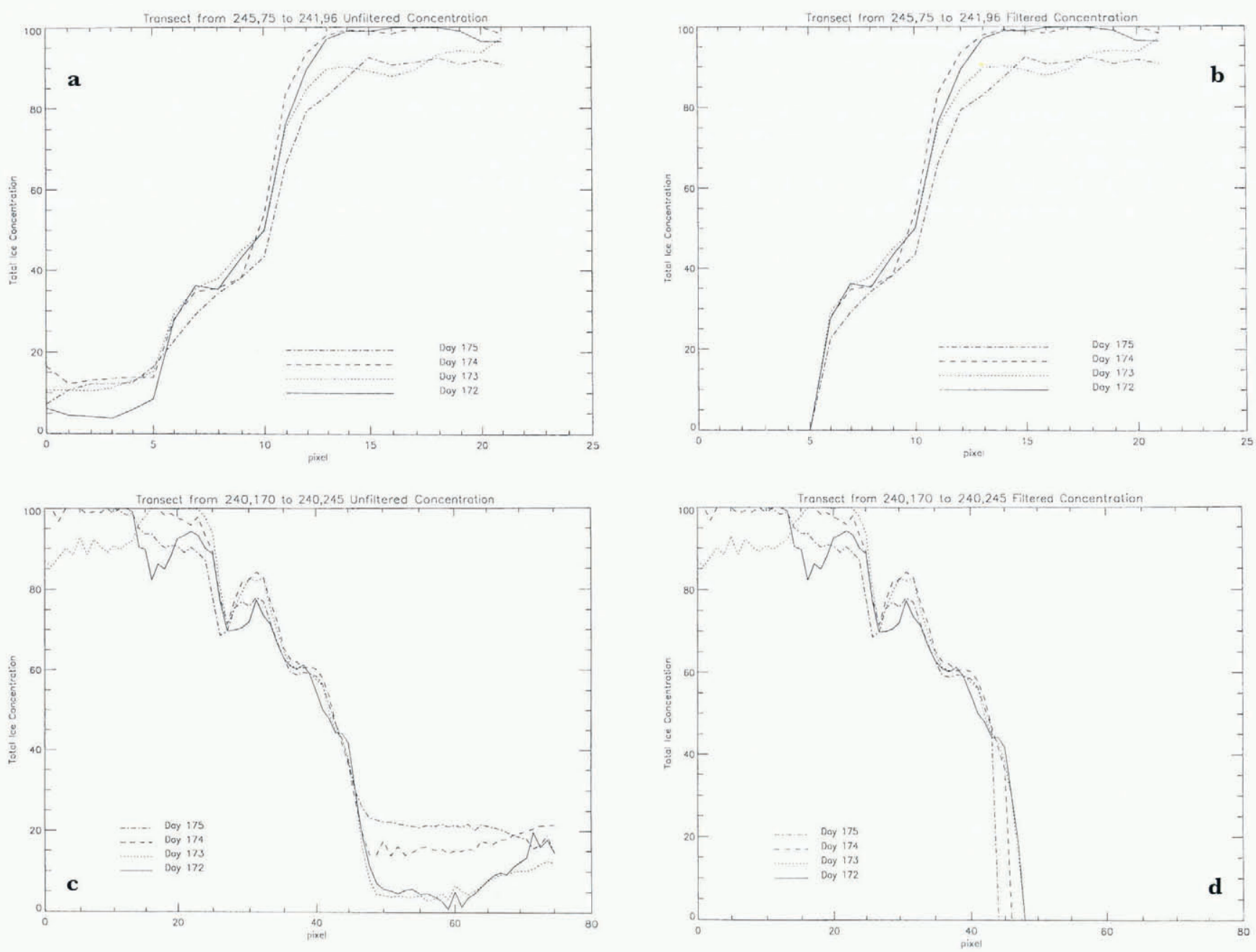

Fig. 8. Sea-ice concentrations from the two transects shown in Figure 7 for a sequence of $4 d$ in 1988. The Beaufort Sea ice concentrations calculated $(a)$ without and $(b)$ with weather filters. The Barents Sea ice concentrations calculaled (c) without and (d) with weather filters.

edge is less successful with the DMSP SSM/I because of the closer proximity of the $19.4 \mathrm{GHz} \mathrm{SSM} / \mathrm{I}$ channels to the $22.2 \mathrm{GHz}$ water-vapor line than that of the $18.0 \mathrm{GHz}$ SMMR channels. An additional filter, based on a combination of the 19.4 and the $22.2 \mathrm{GHz}$ SSM/I channels has been developed to address this problem. The new filter effectively reduces the spurious ice concentrations, especially in the higher latitudes, where such ambiguity poses the greatest problem.

Analysis based on an RTM indicates that the performance of the filter is optimal for winds less than $30 \mathrm{~m} \mathrm{~s}^{-1}$, cloud liquid water less than $0.2 \mathrm{~m}$, water vapor less than $24 \mathrm{~cm}$ and rain rates less than $12 \mathrm{~mm} \mathrm{~h}^{-1}$. Weather exceeding these conditions is uncommon in high latitudes, which supports the observed effectiveness of the filter.

While the technique works well in reducing weather effects in most cases, the trade-off in terms of actual iceconcentration information has not been fully quantified. Our analysis indicates that the actual ice-edge location (defined as $15 \%$ ice concentration) is not affected by the filter. Further validation studies using SAR, AVHRR or OLS data are required to determine conclusively the effect of the filter on ice-edge-location accuracy and the extent to which actual ice information may be lost.

\section{ACKNOWLEDGEMENTS}

The authors gratefully acknowledge many helpful discussions with A. Chang and P. Gloersen during the course of this work. A. Chang kindly provided the brightness temperatures from his rain-rate model used in this paper. We also thank M. Goodberlet for providing the open-ocean wind-speed model. M. Martino and J. Sims of Hughes STX Corp. provided the programming and graphics support. D.J.C. was supported partly by the NASA Cryospheric Processes Program (RTOP 971578-32-20) and partly by the NASA EOS Project 229 04-15-05).

\section{REFERENCES}

Cavalieri, D.J. and 16 others. 1992. NASA sea ice validation program for the DMSP SSM/I: final report. NASA Tech. Memo. 104559 .

Gloersen, P. and F. Barath. 1977. A scanning multichannel microwave radiometer for Nimbus-G and SeaSat-A. IEEE 7 . Oceanic Eng., OE$22,172 \quad 178$.

Gloersen, P. and D.J. Cavalieri. 1986. Reduction of weather effects in the calculation of sea ice concentration from microwave radiances. $\mathcal{F}$. Geophys. Res., 91 C3), 3913-3919.

Gloersen, P., W.J. Campbell, D.J. Cavalieri, J. C. Comiso, C. L. 
Parkinson and H.J. Zwally. 1992. Arctic and Antarctic sea ice, 19781987: satellite passive-microwave observations and analysis. Washington, DC, National Aeronautics and Space Administration. (NASA SP511.)

Maslanik, J.A. 1992. Effects of weather on the retrieval of sea ice concentration and ice type from passive microwave data. Int. $f$. Remote Sensing, 13 1), 37-54.

Nordberg, W., J. Conaway, D. B. Ross and T. Wilheit. 1971. Measurements of microwave emission from a foam-covered winddriven sea. J. Atmos. Sci., 28, 429-435.

St. Germain, K. M. 1993. Applications of spectral microwave radio- metry to sensing of sea ice and the ocean surface. (Ph.D. thesis, University of Massachusetts, Amherst.)

Swift, C. T. 1980. Passive-microwave remote sensing of ocean - a review. Boundary-Layer Meteorol., 18, 25-54.

Ulaby, F. T., R. K. Moore and A. K. Fung. 1981. Microwave remote sensing. Fundamentals and radiometry. Reading, MA, Addison-Wesley Publishing Co.

Wilheit, T. T. and A. T. C. Chang. 1980. An algorithm for retrieval of ocean surface and atmospheric parameters from the observations of the scanning multichannel microwave radiometer. Radio Sci., 15 (3), $525-544$.

MS received 19 September 1994 and accepted 24 January 1995 